\title{
Aprendizagem Autorregulada: estratégias de compreensão leitora
}

\author{
Self-regulated learning: reading comprehension strategies
}

\begin{abstract}
Daiana Corrêa Vieira*, Lourdes Maria Bragagnolo Frison**, Ana Margarida Veiga Simão***
*Professora da rede pública e pesquisadora do Grupo de Estudos e Pesquisa da Aprendizagem Autorregulada Universidade Federal de Pelotas, **Professora da Faculdade de Educação - Universidade Federal de Pelotas, ***Professora da Faculdade de Psicologia - Universidade de Lisboa.
\end{abstract}

\begin{abstract}
Resumo
Este trabalho teve como objetivo investigar se os alunos de uma turma de $8^{\text {a }}$ série do ensino fundamental, de uma escola pública brasileira, melhoraram a compreensão leitora e as competências de autorregulação da leitura, ao participarem de uma intervenção pedagógica. Participaram 27 alunos com idade entre 13 e 16 anos. A metodologia adotada para a intervenção centrou-se na modelagem metacognitiva, interrogação e autointerrogação metacognitiva. Utilizaram-se dois instrumentos: Questionário de Identificação de Estratégias de Compreensão Leitora e Texto com questões de Compreensão Leitora. Dentre outros aspectos importantes, os resultados revelaram que $70,37 \%$ dos alunos apresentaram progressos na compreensão leitora.

Palavras-chave: Aprendizagem autorregulada, estratégias de compreensão leitora, modelagem metacognitiva, interrogação e autointerrogação metacognitiva, intervenção pedagógica.
\end{abstract}

\begin{abstract}
This study aimed to investigate whether students in a 8th grade class of a Brazilian public school elementary improved the reading comprehension and the self-regulation skills of reading, in an educational intervention. Participated 27 students aged between 13 and 16 years. The intervention methodology used the modeling, question and self-question metacognitive. Two instruments were used: Questionnaire of Identification of Reading Comprehension Strategies and Text with questions about Reading Comprehension. Among other important aspects, the results revealed that $70,37 \%$ of students showed progress in reading comprehension.

Keywords: self-regulated learning, reading comprehension strategies, metacognitive modeling, question and metacognitive self-interrogation, pedagogical intervention.
\end{abstract}

A concepção de leitura, neste trabalho, é vista como um processo interativo entre autor e leitor. Nesta perspectiva, o texto passa a ser visto como o ponto de partida para a busca dos sentidos, o signo linguístico passa a ser plurissignificativo e o leitor deixa de ser passivo para tornar-se autor no processo de construção de sentido do texto.
A competência em leitura abarca um conjunto de habilidades que compreende, entre outras, a capacidade do leitor selecionar as suas próprias estratégias de compreensão leitora adequando-as a características variadas dos tipos e gêneros textuais; construir significado; identificar a macroestrutura, a microestrutura e a superestrutura do texto; estabelecer uma rede de relações entre enunciados, organizar e selecionar as informações que compõem as diferentes partes do material; realizar inferências; localizar informações relevantes; avaliar a informação recebida e utilizar adequadamente essa informação (Brandão \& Spinillo, 1998; Solé, 1998).

O domínio da leitura é fator essencial para o estudante obter sucesso escolar, pois a utilização eficiente de estratégias de leitura depende, em parte, do conhecimento que o sujeito possui acerca dessas estratégias. O conceito de estratégias de compreensão leitora é entendido como "procedimentos de caráter elevado, que envolvem a presença de objetivos a serem realizados, o planejamento das ações que se desencadeiam para atingi-los, assim como a sua avaliação e possível mudança” (Solé, 1998, p.70 ).

Segundo Solé (1998), as estratégias anseiam a conquista de um objetivo; singularizam-se porque não estão sujeitas, de forma exclusiva, a um tipo de conteúdo ou a um tipo de texto, podendo adaptar-se a diferentes situações de leitura; envolvem os componentes metacognitivos de controle sobre a sua própria compreensão, pois o leitor especialista, além de compreender, sabe que compreende e quando não compreende.

Em seus estudos sobre aprendizagem autorregulada e estratégias de aprendizagem, Veiga Simão (2002, 2004) correlacionou o processo autorregulatório com o processo de leitura. Desta forma, utilizam-se estratégias autorregulatórias para cada momento da leitura:

i) prévia ou de antecipação da leitura - antes do início propriamente dito da leitura, são estratégias que orientam para o estabelecimento de objetivos, ativação do conhecimento prévio e do conhecimento metacognitivo, ativação de crenças de autoeficácia e de valor da tarefa, planejamento do tempo, esforço e volição, percepções da tarefa e do contexto; 
ii) monitorização da leitura - ocorre durante o processo de ler, são estratégias autorregulatórias que visam monitorar o processo de compreensão leitora, orientam para a consciência metacognitiva, para a auto-observação da cognição e do comportamento, para a monitorização da motivação, do esforço, do tempo, da necessidade de ajuda, das condições da tarefa e do contexto;

iii) avaliação da leitura - pode ocorrer ao longo e após a leitura. As estratégias aqui empregadas visam avaliar a compreensão que o sujeito teve ao ler o texto e como ocorreu o processo de ler, referem-se, ainda, aos processos de autoavaliação que influenciam a alteração do comportamento (continuar, desistir) frente à tarefa.

Embora as pessoas possuam as habilidades necessárias para serem autorreguladas, elas não são necessariamente autorreguladas em todos os aspectos, ou seja, o sujeito pode ser autorregulado para alguma atividade do seu cotidiano e para outras não.

O construto da autorregulação diz respeito ao modo como o sujeito gerencia seu comportamento, sua motivação, seus sentimentos e emoções, o ambiente físico e social, de forma consciente e intencional.

Zimmerman (1990, 2013), Pintrich (2000) e Boekaerts \& Corno (2005), afirmam que todo sujeito consegue regular a sua própria aprendizagem, ou seja, a autorregulação é compreendida como um mecanismo que potencializa os processos de realização acadêmica, envolve as dimensões cognitiva e metacognitiva, motivacional, comportamental e afetiva e, permite que o sujeito ajuste suas ações a fim de alcançar os objetivos delineados. Pode-se afirmar que os alunos regulam a sua própria aprendizagem ao utilizarem estratégias cognitivas, metacognitivas, motivacionais e comportamentais (Veiga Simão, 2004; Frison, 2007).

É importante ressaltar, que existem entre as muitas concepções epistemológicas acerca da definição do construto da aprendizagem autorregulada, algumas características comuns sobre os processos autorregulatórios, como: i) é um processo cíclico em que os estudantes planejam suas ações, monitoram a eficácia de suas estratégias e reagem ao feedback (positivo ou negativo) que pode ser do(a) professor(a), pais, colegas etc., sobre o resultado obtido da tarefa; ii) utiliza estratégias autorregulatórias (cognitivas, metacognitivas, motivacionais e comportamentais); iii) indica como e por que os estudantes optam por usar uma estratégia ou resposta específica, requerendo tempo de preparação, monitoramento e esforço (Zimmerman, 1990; Pintrich, 2000; Veiga Simão, 2002; Rosário, 2004; Frison, 2007).

Desta forma, as estratégias de compreensão leitora necessitam ser úteis, generalizáveis e transferíveis para serem utilizadas com diferentes objetivos para tipos e gêneros textuais variados. Assim, os alunos ao se apropriarem do conhecimento sobre as estratégias autorregulatórias de leitura, têm a possibilidade de escolher as que são mais eficazes para o momento da leitura, de acordo com a exigência da tarefa e com a característica que o texto apresenta. Além disso, a organização e a estruturação do ambiente de aprendizagem adequado, a adoção de um comportamento ativo frente às atividades escolares, o monitoramento e a avaliação das ações estão entre as atuações necessárias para a promoção de competências autorregulatórias para a leitura.

\section{Método}

\section{Participantes}

Esta pesquisa foi realizada com 27 alunos, 14 do gênero masculino e 13 do feminino, com idade entre 13 e 16 anos, todos de nacionalidade brasileira, que cursavam a $8^{\mathrm{a}}$ série do ensino fundamental, no turno matutino, do Instituto Estadual de Educação Ponche Verde, localizado no município de Piratini/RS.

A participação dos alunos no estudo ocorreu de forma voluntária. Foi solicitado aos pais/responsáveis que assinassem um Termo de Consentimento Livre e Esclarecido autorizando a utilização e divulgação dos dados produzidos ao longo da pesquisa.

\section{Instrumentos}

Dois instrumentos foram utilizados para a coleta de dados:

1. Questionário de Identificação de Estratégias de Compreensão da Leitura (QIECL). Este questionário teve o objetivo de identificar as estratégias de compreensão leitora (antecipação, monitorização e avaliação da leitura) utilizadas pelos alunos do ensino fundamental, originalmente planejado para os estudantes do $5^{\circ}$ ano em Portugal. O QIECL integra o Projeto de Intervenção em contexto de sala de aula - Aprendizagem e Ensino de Estratégias de Compreensão Leitora de Veiga Simão (2013) e foi adaptado para o contexto brasileiro de $8^{\text {a }}$ série do ensino fundamental pelo Grupo de Estudos e Pesquisa da Aprendizagem Autorregulada (GEPAAR). Ele é composto por 24 perguntas do tipo escala Likert com opções de frequência: sempre ou quase sempre, muitas vezes, algumas vezes, pouquíssimas vezes e nunca ou quase nunca, 4 questões com opções de sim ou não e 3 questões com várias alternativas. Aplicado antes e após a intervenção pedagógica.

2. Texto com questões de compreensão leitora (TCL). Este instrumento de avaliação foi aplicado em dois momentos da pesquisa, antes e após a intervenção pedagógica. Utilizaram-se dois textos, com predominância narrativa, retirados do livro didático de Língua Portuguesa, adotado pela escola para a $8^{\mathrm{a}}$ série do ensino fundamental. Os textos escolhidos para os dois momentos já descritos contemplaram as seguintes características: i) serem do livro didático adotado pela escola, ii) apresentarem predominância narrativa, iii) apresentarem temática que discutisse questões sociais; iv) possuírem um número aproximado de palavras. Estes critérios basearam-se na concepção de que, para uma compreensão eficaz, o texto necessita ser compatível com o nível de competência do leitor, com a idade e a série, que o contexto favoreça a compreensão do texto e que o leitor consiga reunir os conhecimentos (prévios) para a compreensão (Giasson, 1993; Solé, 1998). 


\section{Procedimentos}

Esta investigação se desenvolveu a partir de uma pesquisa tipo intervenção pedagógica ${ }^{1}$, em contexto de sala de aula, inserindo-se na modalidade de infusão curricular (Rosário, 2004), cujo objetivo é integrar o ensino de estratégias de aprendizagem na dinâmica das áreas curriculares.

Após o recebimento do Termo de Consentimento Livre e Esclarecido da pesquisa assinado pelos pais/responsáveis dos participantes, passou-se para a aplicação dos instrumentos - QIECL e TCL, os quais tiveram a duração de dois períodos (1h40min). Os participantes foram orientados a responderem os instrumentos de acordo com as suas instruções.

$\mathrm{Na}$ aula seguinte à aplicação dos instrumentos, teve início a intervenção pedagógica, a qual foi desenvolvida ao longo de onze sessões-aula, na disciplina de Língua Portuguesa, semanalmente, durante dois períodos (1h40min), mediada pela professora da turma e também pesquisadora desta investigação.

A metodologia adotada para a intervenção pedagógica foi a modelagem metacognitiva, interrogação e autointerrogação metacognitiva, atrelada aos guias de interrogação metacognitiva e aos cartões-registro, a qual proporciona, por um lado, que o aluno tome consciência do que faz e para que faz, oportunizando mudanças no sentido de dar prosseguimento aos objetivos definidos e, por outro lado, pode funcionar como um feedback interno, o qual permite ao estudante autoavaliar a sua aprendizagem (Veiga Simão, 2004).

Ao longo das sessões-aula foram trabalhados três textos e, para cada texto trabalhado, desenvolveram-se estratégias autorregulatórias de antecipação e planejamento da leitura, monitorização da leitura, avaliação da leitura e autoavaliação, por meio da co-construção de guias de interrogação metacognitiva. Também foram co-construídos cartões-registro que objetivavam a avaliação do próprio processo de aprendizagem pelos estudantes.

Após o término da intervenção pedagógica, foram aplicados os instrumentos QIECL e TCL, obedecendo a mesma dinâmica inicial.

\section{Resultados}

Os dados obtidos neste estudo foram submetidos à técnica de análise de conteúdo (Bardin, 1979). No que concerne aos avanços relativos ao nível de compreensão leitora dos alunos, analisou-se a estratégia sublinhar as ideias principais do texto, as questões referentes à compreensão textual e a compreensão, por meio da escrita, que o aluno construiu a partir da leitura do texto, através do instrumento: Texto com questões de Compreensão Leitora (TCL), aplicado antes e após a intervenção pedagógica. As tabelas a seguir, trazem os resultados encontrados neste instrumento.

${ }^{1}$ Caracterizada por ser um tipo de pesquisa educacional "no qual práticas de ensino inovadoras são planejadas, implementadas e avaliadas em seu propósito de maximizar as aprendizagens dos alunos que delas participam” (Damiani, 2012, p. 2).
Na tabela 1 é possível perceber, com relação à estratégia sublinhar as ideias principais do texto, antes da intervenção pedagógica, que dos 27 alunos da turma, 4 sublinhavam integralmente, 12 sublinhavam parcialmente e 11 não conseguiam identificá-las.

Para esta estratégia, observa-se que a turma apresentou avanços significativos após a intervenção pedagógica, mais 11 alunos passaram a sublinhar as ideias principais do texto (antes 4, após 15), menos 4 sublinharam parcialmente (antes 12, após 8) e menos 9 foram os alunos que não sublinharam nenhuma das ideias principais (antes 11, após 2).

Tabela 1

Identificação das ideias principais do texto - TCL

\begin{tabular}{|c|c|c|c|c|c|}
\hline Indicador & & Antes & & Após & \\
\hline \multirow{5}{*}{$\begin{array}{l}\text { Sublinhar } \\
\text { as ideias } \\
\text { principais } \\
\text { do texto }\end{array}$} & & $\mathrm{n}$ & $\%$ & $\mathrm{n}$ & $\%$ \\
\hline & $\begin{array}{l}\text { Sublinhou } \\
\text { integralmente }\end{array}$ & 4 & 14,81 & 15 & 56,56 \\
\hline & $\begin{array}{l}\text { Sublinhou } \\
\text { parcialmente }\end{array}$ & 12 & 44,74 & 8 & 29,63 \\
\hline & $\begin{array}{l}\text { Não sublinhou } \\
\text { nenhuma das } \\
\text { ideias principais }\end{array}$ & 11 & 40,74 & 2 & 7,41 \\
\hline & Não respondeu & 0 & 0,00 & 2 & 7,41 \\
\hline
\end{tabular}

A tabela 2 mostra os resultados referentes às questões de compreensão do texto, antes e após a intervenção pedagógica. Inicialmente, 9 estudantes conseguiram compreender o que liam, 8 tiveram uma compreensão parcial e 10 alunos não entenderam o assunto abordado no texto.

Observa-se que, após a IP, houve melhora com relação a estas questões, pois mais 6 alunos passaram a compreender as questões referentes ao texto (antes 9, após 15). É possível verificar também, que diminuiu o índice de estudantes que não haviam conseguido compreendê-las plenamente, antes eram 10 alunos (37,04\%) e após a IP, incidiram em 5 alunos (18,52\%).

Tabela 2

Questões referentes à compreensão do texto - TCL

\begin{tabular}{|c|c|c|c|c|c|}
\hline Indicador & & Antes & & Ipós & \\
\hline \multirow{5}{*}{$\begin{array}{l}\text { Questões } \\
\text { referentes à } \\
\text { compreensão } \\
\text { do texto }\end{array}$} & & $\bar{n}$ & $\%$ & $\mathrm{n}$ & $\%$ \\
\hline & Compreendeu & 9 & 33,33 & 15 & 55,56 \\
\hline & $\begin{array}{l}\text { Compreendeu } \\
\text { parcialmente }\end{array}$ & 8 & 31,48 & 7 & 25,93 \\
\hline & $\begin{array}{l}\text { Não houve } \\
\text { compreensão }\end{array}$ & 10 & 37,04 & 5 & 18,52 \\
\hline & Não respondeu & 0 & 0,00 & 0 & 0,00 \\
\hline
\end{tabular}

A seguir, a tabela 3 apresenta os dados relativos à compreensão que os alunos tiveram ao ler o texto, por meio da escrita. Antes da intervenção pedagógica 8 expressaram-se plenamente, 8 parcialmente e 11 alunos não conseguiram expressar o que compreenderam ao ler o texto.

De um modo geral, como é possível observar, a turma apresentou progressos importantes quando comparada aos dois momentos de avaliação do instrumento, uma vez que passou de 29,63\% (8 alunos) para 51,85\% (14 alunos) o percentual de estudantes que conseguiram 
expressar o que entenderam com a leitura do texto, ou seja, um acréscimo de 6 alunos. Ao mesmo tempo, diminuiu o número de estudantes que não acertaram esta questão (antes 11, após 5).

Tabela 3

Expressar, por meio da escrita, a compreensão que teve ao ler o texto - TCL

\begin{tabular}{llrrrrr}
\hline \multicolumn{1}{c}{ Indicador } & & Antes & \multicolumn{3}{c}{ Após } \\
\hline & & $\mathrm{n}$ & $\%$ & $\mathrm{n}$ & $\%$ \\
\cline { 2 - 7 } & $\begin{array}{l}\text { Expressou-se } \\
\text { plenamente }\end{array}$ & 8 & 29,63 & 14 & 51,85 \\
$\begin{array}{l}\text { Expressar, por } \\
\text { meio da escrita, a } \\
\text { compreensão que } \\
\text { teve ao ler oxpressou-se } \\
\text { texto. }\end{array}$ & 8 & 29,63 & 7 & 25,93 \\
\cline { 2 - 7 } & $\begin{array}{l}\text { Earcialmente } \\
\text { Não conseguiu } \\
\text { expressar } \\
\text { Não respondeu }\end{array}$ & 11 & 40,74 & 5 & 18,52 \\
& & 0 & 0,00 & 1 & 3,70 \\
\hline
\end{tabular}

No tocante à análise das estratégias autorregulatórias de leitura, a figura 1 apresenta uma síntese dessas estratégias reveladas no QIECL e nos guias de interrogação metacognitiva, após a intervenção pedagógica. Cabe ressaltar que estas estratégias foram empregadas por estudantes que apresentaram maior compreensão leitora.

\begin{tabular}{|c|c|c|}
\hline $\begin{array}{l}\text { Momentos da } \\
\text { leitura }\end{array}$ & $\begin{array}{c}\text { Estratégias utilizadas } \\
\text { no QIECL }\end{array}$ & $\begin{array}{l}\text { nos Guias de } \\
\text { Interrogação } \\
\text { Metacognitiva }\end{array}$ \\
\hline Antecipação & $\begin{array}{l}\text { - ler o título } \\
\text {-observar imagens, } \\
\text { pensar sobre o que o } \\
\text { texto irá abordar } \\
\text { - ter objetivos para ler } \\
\text { - relembrar o que sabe } \\
\text { sobre o assunto do } \\
\text { texto } \\
\text { - pensar por que o(a) } \\
\text { professor(a) solicitou a } \\
\text { leitura do texto }\end{array}$ & $\begin{array}{l}\text { - ler o título } \\
\text { - ter um objetivo para } \\
\text { a leitura } \\
\text { - ter hipóteses } \\
\text { - observar imagens, } \\
\text { ilustrações, gráficos } \\
\text { - pensar sobre como } \\
\text { ler o texto } \\
\text { - pensar sobre o que o } \\
\text { texto irá abordar } \\
\text { - pensar o que sabe } \\
\text { sobre o assunto }\end{array}$ \\
\hline Monitorização & $\begin{array}{l}\text { - ler com atenção e } \\
\text { devagar } \\
\text { - nunca ler o texto } \\
\text { rapidamente } \\
\text { - não passar à frente } \\
\text { partes do texto } \\
\text { - não desistir de ler o } \\
\text { texto } \\
\text { - concentrar-se na } \\
\text { leitura }\end{array}$ & $\begin{array}{l}\text { - ler devagar } \\
\text { - reler partes do texto } \\
\text { que não compreendeu } \\
\text { - concentrar-se na } \\
\text { leitura do texto } \\
\text { - tentar compreender } \\
\text { as palavras } \\
\text { desconhecidas pelo } \\
\text { contexto } \\
\text { - imaginar a história, } \\
\text { personagens } \\
\text { enquanto lê } \\
\text { - pensar sobre o que o } \\
\text { texto propõe }\end{array}$ \\
\hline Avaliação & $\begin{array}{l}\text { - relembrar as ideias } \\
\text { principais } \\
\text { - ler novamente partes } \\
\text { do texto quando não } \\
\text { entender } \\
\text { - escrever o que } \\
\text { entendeu do texto com } \\
\text { palavras próprias } \\
\text { - reler o texto com a } \\
\text { intenção de } \\
\text { compreendê-lo } \\
\text { - nunca copiar trecho } \\
\text { do texto de forma } \\
\text { literal }\end{array}$ & $\begin{array}{l}\text { - questionar-se sobre } \\
\text { o texto } \\
\text { - identificar as ideias } \\
\text { principais } \\
\text { - pensar sobre o que } \\
\text { trata o texto } \\
\text { - resumir o texto com } \\
\text { palavras próprias } \\
\text { - formular perguntas } \\
\text { sobre o texto }\end{array}$ \\
\hline
\end{tabular}

Figura 1 - Resumo das estratégias de compreensão leitora
Como pode ser visto na figura 1 , entre as estratégias de antecipação da leitura mais citadas nos guias de interrogação metacognitiva, encontraram-se: ler o título, estabelecer um objetivo para ler, ter hipóteses, observar imagens, ilustrações, gráficos, pensar sobre como ler o texto, pensar sobre o que o texto irá abordar e pensar o que sabe sobre o assunto. No QIECL, além dessas estratégias, os alunos acrescentaram o pensar sobre o porquê o(a) professor(a) solicitou a leitura do texto.

As estratégias de monitorização, reveladas nos guias, compreenderam: ler devagar, reler partes do texto quando não compreender, concentrar-se na leitura do texto, tentar compreender as palavras desconhecidas pelo contexto, imaginar a história e/ou personagens enquanto lê e pensar sobre o que o texto propõe. No QIECL, as estratégias: nunca ler o texto rapidamente, não passar à frente partes do texto e não desistir de ler o texto, foram agregadas às empregadas nos guias.

As estratégias de avaliação da leitura mais mencionadas nos guias foram: questionar-se sobre o texto, identificar as ideias principais, pensar sobre o que trata o texto, resumir o texto com palavras próprias e formular perguntas sobre o texto. Elas vêm ao encontro das referenciadas no QIECL, além destas, os estudantes assinalaram: ler novamente partes do texto quando não entender, reler o texto com a intenção de compreendê-lo e nunca copiar trecho do texto de forma literal.

\section{Discussão}

O presente estudo teve como objetivo geral investigar se os alunos de uma turma de $8^{\mathrm{a}}$ série do ensino fundamental, de uma escola pública brasileira, melhoraram a compreensão leitora e as competências de autorregulação da leitura, ao participarem de uma intervenção pedagógica; como objetivo específico, analisar se os dados coletados nos instrumentos aplicados antes da intervenção, comparados com os da pós-intervenção, demonstraram avanços no nível de compreensão leitora dos alunos.

Ao analisar os dados referentes ao instrumentos TCL (tabelas 1, 2 e 3), pode-se constatar que, de modo geral, a turma apresentou avanços, substanciais, relativos ao sublinhar as ideias principais do texto, às questões que dizem respeito à compreensão textual e, também avançou com relação ao expressar, por meio da escrita, o que compreendera do texto.

Os resultados revelaram que 19 alunos (70,37\%) apresentaram progressos ao menos em duas das quatro questões do instrumento de avaliação TCL. Neste sentido, notou-se que o desempenho dos participantes foi melhor após a intervenção pedagógica. A diferença constatada após a IP pode ter ocorrido devido ao ensino explícito de estratégias de aprendizagem, especialmente as de compreensão leitora. Pesquisadores como Solé (1998), Palincsar (2003), Boruchovitch (2001), Veiga Simão (2002, 2004), propõem o ensino explícito de estratégias de leitura, o qual necessita ser intensivo e 
extensivo, como parte integrante dos diferentes conteúdos curriculares.

Pode-se afirmar que, no contexto deste trabalho, as estratégias autorregulatórias de compreensão leitora auxiliaram tanto na avaliação do processo de ler como na compreensão propriamente dita, ou seja, no entendimento que o estudante teve ao ler um texto. Nesta perspectiva, o ensino da leitura necessita estar correlacionado à avaliação do que é ou não compreendido, para que o aluno possa construir um significado a propósito do texto e, também, à avaliação das estratégias que permitem compensar quando não há compreensão.

É importante ressaltar que programas de intervenção pedagógica relacionados ao ensino de estratégias de leitura, que se assemelham ao estudo realizado, apresentaram resultados semelhantes aos encontrados nesta pesquisa (Oliveira, Boruchovitch \& Santos 2007; Gomes \& Boruchovitch, 2011; Frade; 2011).

No que concerne ao emprego das estratégias autorregulatórias de leitura (figura 1), revelado no QIECL e nos guias de interrogação metacognitiva, os resultados indicam que os estudantes que apresentaram maior compreensão leitora são também os que utilizaram um repertório maior e mais variado de estratégias de antecipação e de planejamento, de monitorização e de avaliação da leitura.

Solé (1998) e Veiga Simão (2004) ressaltam que é fundamental que os alunos saibam utilizar as estratégias adequadas para a compreensão do texto, ou seja, o simples uso de estratégias, sem intencionalidade e consciência metacognitiva, não assegura que o sujeito consiga ter compreensão do que lê. Neste sentido, compreende-se que as atividades cognitivas e metacognitivas precisam ser ativadas ou fomentadas mediante as estratégias.

Diante disso, o emprego de uma gama diversificada de estratégias pode ter contribuído para um melhor desempenho na compreensão leitora do grupo analisado, uma vez que as estratégias assinaladas no questionário (QIECL) e escritas nos guias de interrogação metacognitiva, vêm ao encontro das descritas na literatura por Palincsar (2003) e Gomes \& Boruchovitch (2011), como as que potencializam a compreensão leitora e colaboram para que o aluno se constitua em um leitor proficiente, ou melhor, um leitor que saiba usar as estratégias mais adequadas para compreender os textos que lê.

A partir do exposto, é possível pensar que, no formato apresentado, a metodologia utilizada na intervenção pedagógica - modelagem metacognitiva, interrogação e autointerrogação metacognitiva, contribuiu para que os alunos desenvolvessem competências autorregulatórias, as quais colaboraram para uma melhor compreensão dos textos trabalhados. Os resultados revelaram que os estudantes ao adotarem um pensamento estratégico, passaram a utilizar um repertório maior e também variado de estratégias. É importante ressaltar que os estudantes foram se apropriando das estratégias e utilizando-as com maior habilidade e propriedade ao longo das sessões-aula, ao fazerem uso dos guias de interrogação metacognitiva e dos cartões-registro.
Todavia, por se tratar de processos de ensino e de aprendizagem, é necessário que essas estratégias autorregulatórias sejam trabalhadas em todas as disciplinas, no decorrer do ano letivo, ou melhor, na modalidade de infusão curricular.

\section{Referências}

Bardin, L. (1979). Análise de conteúdo. Lisboa: Edições. Boekaerts, M. \& Corno, L. (2005). Self-Regulation in the Classroom: A perspective on Assessment and Intervention. Applied Psychology: An International Review. No2/Vol54, pp. 199-231.

Boruchovitch, E. (2001). Algumas estratégias de compreensão em leitura de alunos do Ensino Fundamental. Psicologia Escolar e Educacional. No1/Vol5, pp.19-25.

Brandão, A. C. \& Spinillo, A. G. (1998). Aspectos gerais e específicos na compreensão de textos. Psicologia: Reflexão e Crítica. No2/Vol11, pp.253-272.

Damiani, M. F. (2012). Sobre Pesquisas do tipo intervenção. In: Anais do XVI Encontro Nacional de Didática e Prática de Ensino. (pp.2882-2890) Campinas: Unicamp.

Frade, C. L. D. (2011). Auto-questionamento e Identificação de Estratégias de Metacompreensão Leitora, perante a tarefa, em alunos do $5^{\circ}$ ano de escolaridade - Estudo Exploratório. Dissertação (Mestrado Integrado em Psicologia)- Faculdade de Psicologia, Universidade de Lisboa, Lisboa, Portugal.

Frison, L. M. B. (2007). Auto-regulação da aprendizagem. Ciência e Conhecimento - Revista da Ulbra,Vol.02, pp.1-14.

Giasson, J. (1993). A compreensão na leitura. Lisboa: Edições Asa.

Gomes, M. A. M. \& Boruchovitch, E. (2011) Aprendizagem autorregulada da leitura: resultados positivos de uma intervenção psicopedagógica. Psicologia: Teoria e Pesquisa, N³/Vol.27, pp.291-299.

Oliveira, K. L., Boruchovitch, E., \& Santos, A. A. A.(2007). Compreensão de leitura em alunos de sétima e oitava séries do ensino fundamental. Psicologia Escolar e Educacional. Vol.11, pp.41-49.

Palincsar, A. (2003). Collaborative Approaches to reading comprehension. In A. \& Sweet C. Snow (Eds.). Rethinking reading comprehension. (pp.99-115). New York: Guilford Press.

Pintrich, P. R. (2000). The role of goal orientation in self-regulated learning. In: M. Boekaerts, P. Pintrich \& M. Zeidner (Eds.). Handbook of self-regulation. (pp.451-502). San Diego: Academic Press.

Rosário, P. (2004). Estudar o Estudar: As (Des)venturas do Testas. Porto: Porto Editora.

Solé, I. (1998). Estratégias de leitura. Porto Alegre: Artmed.

Veiga Simão, A. M. (2002). Aprendizagem estratégica: uma aposta na auto-regulação. Desenvolvimento curricular. Ministério da Educação, Lisboa.

Veiga Simão, A. M. (2004). O conhecimento estratégico e a auto-regulação da aprendizagem: implicações em contexto escolar. In. A. Lopes da Silva, A. Duarte, I. Sá 
\& A. M. Veiga Simão (Orgs.) Aprendizagem auto-regulada pelo estudante: perspectivas psicológicas e educacionais (pp.77-94). Lisboa: Porto Editora.

Zimmerman, B. J. (1990). Self-regulated Learning and Academic Achievement: An Overview.
Educational Psychologist. No1/Vol.25, pp.3-7.

Zimmerman, B. J.(2013). From cognitive modeling to self-regulation: a social cognitive carrier path. Educational Psychologist. No3/Vol. 48, pp.135-147. 